ORIGINAL ARTICLE

\title{
Parental occupation at periconception: findings from the United Kingdom Childhood Cancer Study
}

\author{
P A McKinney, N T Fear, D Stockton, on behalf of the UK Childhood Cancer Study Investigators*
}

Occup Environ Med 2003;60:901-909

See end of article for authors' affiliations

Correspondence to:

Dr P McKinney, Principal

Researcher, Information

and Statistics Division of the CSA for NHS Scotland,

Trinity Park House,

Edinburgh EH5 3SQ, UK

p.a.mckinney@leeds.ac.uk

Accepted

7 November 2002

\begin{abstract}
Aims: To study the risk of childhood cancer in relation to parental occupation and related exposures. Methods: Self reported occupational data from mothers and fathers of 3838 children with cancer and 7629 control children were analysed. Odds ratios were calculated for 31 "occupational groups" by parent, diagnostic group (leukaemia, acute lymphoblastic leukaemia (ALL), central nervous system tumours, and other cancers) and time of exposure (periconception, birth, and diagnosis).

Results: Findings did not support the hypothesis that occupational exposure of fathers to ionising radiation increases the risk of childhood cancer in their offspring. Specific examination of periconceptual chemical exposures showed small but statistically significant increased risks for leukaemia and ALL among children whose fathers were exposed to exhaust fumes, driving, and/or inhaled particulate hydrocarbons. In the remaining analyses, a fourfold increase in the risk of other cancers was observed among the children of fathers working with leather but based on small numbers. Both maternal and paternal exposure to textile dust was related to an increased risk of other cancers.

Conclusion: Results failed to produce any strong evidence to link parental occupational exposures with an increased risk of childhood cancer. No relation was found for paternal periconceptual exposure to ionising radiation. The consistency of the associations observed between childhood leukaemia and paternal occupational exposure to exhaust fumes, driving, and/or inhaled particulate hydrocarbons at periconception suggest a small risk for vehicle related exhaust. However, other explanations cannot be excluded and further research into the nature of the associations is required.
\end{abstract}

S ome working environments have been reported to increase the risk of malignant disease among adults ${ }^{1}$ and concern that potentially carcinogenic occupational exposures may carry increased risk to offspring of workers has long been of interest. However, the published literature reveals little consistency in relation to risk factors and the rarity of childhood cancers, the low prevalence of many occupational exposures, and the lack of good exposure assessment hamper interpretation. Two recent reviews have highlighted these difficulties. ${ }^{2}{ }^{3}$

The biological mechanisms that may explain potential associations between parental occupation and childhood cancer are unclear. Their plausibility depends not only on the type of malignancy but also which parent is exposed as well as the timing and route of exposure. Preconception exposures are postulated to involve the parental germ cells, intrauterine exposures the developing fetus, and postnatal exposures the child directly. ${ }^{4}$

The United Kingdom Childhood Cancer Study (UKCCS), a large population based case-control study, was established in 1991 to investigate possible causes of childhood cancer. ${ }^{5}$

At the outset five broad aetiological hypotheses were identified, of which the following has been specifically addressed by our report "Childhood cancer may be caused by exposure of the parental germ cells before the child's conception to radiation or hazardous chemicals". We present analyses based on the occupational histories of mothers and fathers reported at interview. Our approach has focused on exposures of interest (rather than specific jobs) by grouping job titles into "occupational groups" according to their

*A complete list of investigators is given in: "UK Childhood Cancer Study Investigators. The United Kingdom Childhood Cancer Study: objectives, material, and methods" (Br J Cancer 2000;82:1073-102) likelihood of exposure. Results are presented for occupational exposures occurring at periconception and interpreted in the context of findings from exposures at the time of diagnosis.

\section{METHODS}

Details of the study's methodology are given elsewhere. ${ }^{5}$ Briefly, eligible case subjects were children (aged 0 to 14 years) diagnosed with a malignant disease or specified benign tumour between 1991 and 1996, while resident in England, Scotland, and Wales.

For each case, two control children randomly selected from the same Family Health Services Authority (FHSA) in England and Wales and Health Boards in Scotland were individually matched by sex, age (month and year of birth), and geographical area (at diagnosis).

Parents of 3838 case children and 7629 control children were interviewed, representing participation rates of $87 \%$ and $64 \%$ respectively.

Diagnoses for the 3838 interviewed cases were:

- Leukaemia; 1737 cases (45\%)

- Acute lymphoblastic leukaemia (ALL) (a subset of leukaemia); 1461 cases (38\%)

- Central nervous system (CNS) tumours; 687 cases (18\%)

- Other cancers (excludes leukaemia and CNS tumours); 1414 cases $(37 \%)$.

Abbreviations: ALL, acute lymphoblastic leukaemia; CASOC, Computer Assisted Standard Occupational Classification; 95\% Cl, 95\% confidence interval; CNS, central nervous system; FHSA, Family Health Services Authority; HD, Hodgkin's disease; OR, odds ratio; UKCCS, United Kingdom Childhood Cancer Study 
Main messages

- The UKCCS provides an opportunity to evaluate the risk of childhood cancer in relation to parental occupation and related exposures.

- Small but statistically significant increased risks were observed for leukaemia and ALL among children whose fathers were exposed to exhaust fumes, driving, and/or inhaled particulate hydrocarbons at periconception.

- A cautious interpretation of these findings is required as the data are self reported, the exposure assessment may lack precision, and the large number of comparisons made may result in some statistically significant associations arising by chance.

\section{Data collection}

Personal interviews with each parent of the index child gathered a range of demographic, social and health related information, including a complete occupational history. ${ }^{5}$

To assist with data collection, parents were asked to complete a "pre-interview form" regarding their job history; using this the interviewer recorded all jobs held for over six months from leaving full time education until the time of interview. Details requested for each job included job title, duties, industrial setting, and month and year of starting and finishing; information was collected on part time work and employment in more than one job at any given time.

If a parent was not present at the interview, surrogate information on occupational histories was taken mainly from spouses. Attempts were always made to interview mothers, of whom $1.7 \%$ of cases and $1.1 \%$ of controls had surrogate details recorded. For fathers, there was surrogate information for $12.7 \%$ of cases and $24.3 \%$ of controls. The higher proportion of proxy details for the control fathers reflects the priority of obtaining an interview with the control mother, although fathers were encouraged to be present and were frequently followed up by telephone for occupational history information.

\section{Occupational coding}

Each job title and associated industry was coded according to the 1990 Standard Occupational Classification ${ }^{6}$ and the 1992 Standard Industrial Classification of Economic Activities, respectively. Occupational coding was completed by nine UKCCS coding centres (covering 10 UKCCS regions) using either coding manuals exclusively (four centres), or coding manuals supplemented by the Computer Assisted Standard Occupational Classification (CASOC) $)^{8}$ (four centres) or CASOC alone (one centre); industrial coding was via the coding manual. ${ }^{7}$

The reliability of job coding was checked through periodic spot checks and duplicate coding of a 5\% random sample of complete job histories from each of the nine study regions, by two independent coders. The sample comprised 1047 parents contributing 4542 occupations; the level of agreement was $75 \%$ (range by region $66-79 \%$ ), which is in line with other studies that have attempted to quantify the reliability of different coders. ${ }^{\circ}$

\section{Measures of exposure}

"Occupational groups" were constructed by combining job titles considered to be homogeneous for specific exposures. This classification is based on a scheme developed for use with the 1970 occupational classification, ${ }^{10-14}$ which has
Policy implications

- Risks associated with occupational exposures are difficult to evaluate because of the lack of good exposure assessment.

- Plausible biological mechanisms should be explored to explain the potential associations between certain parental occupations (and related exposures) and childhood cancer.

subsequently been updated for use with the 1990 classification. ${ }^{6}{ }^{15}$ An experienced expert group (occupational hygienist (B Pannett), epidemiologist (NT Fear), and research officer (K Baker)) created the occupational groups independently of the data using job descriptions, epidemiological literature involving occupational exposures, and industrial monitoring data. In addition, several independent experts and organisations were consulted (Professor JM Harrington; Dr J Charlton; Health and Safety Executive; National Radiological Protection Board; National Grid).

The 371 jobs from the 1990 occupational classification were categorised into one or more of 31 occupational exposure groups (available from the authors). Hydrocarbons were divided into dermal (skin/epidermal) exposures and inhaled particulate exposure; metals were subdivided into acid mists (from metal treating operations), metal fumes, and oil mists (from metal machining operations) to allow for differing routes or types of exposure.

Each of the 371 occupations was assigned as having definite, possible, or unlikely exposure to each of the 31 groups. "Definite" exposure reflects contact with the specified agent either everyday or at very high levels (for example, carpenters and wood dust). "Possible" exposure includes jobs where exposure might occur but not necessarily daily or at very high levels (for example, builders and wood dust). Twenty one "generic" occupational codes (for example, "packers, bottlers, canners, fillers", "weighers, graders, sorters") were assigned as possibly exposed using supplementary information on industry, where appropriate. Eighty occupational codes, not categorised into any of the 31 occupational groups, were classified as "unlikely" for all groups.

\section{Timing of exposure}

Parental occupational exposures occurring at periconception, birth, and diagnosis (of the index child) were analysed; these time points correspond to the different biological mechanisms identified for preconception, fetal, and childhood exposure. Exposure at periconception was defined as the job held one year prior to the birth of the child and analysis was restricted to natural parents; for exposures at birth and diagnosis, non-natural parents were included if they were living with the child at the relevant time point.

In order to allocate an occupation to each time point of interest, some incomplete or missing start and finish dates needed to be assigned/imputed based on an algorithm using the available data. The percentage of parents for whom dates of employment were imputed at any time point comprised $27 \%$ of cases and $26 \%$ of controls for incomplete dates and $0.7 \%$ of cases and $0.8 \%$ of controls for missing dates.

\section{Statistical analysis}

Odds ratios (OR) and 95\% confidence intervals (95\% CI) were computed using unconditional logistic regression ${ }^{16}$ to permit the inclusion of unmatched cases and controls, with all 
analyses being routinely adjusted for age at diagnosis in single years (0 to 14), sex, and UKCCS region ( 10 in total). All controls were used as the comparison group for each diagnostic group, an approach previously adopted in other UKCCS analyses. ${ }^{17}{ }^{18}$ For each analysis, the baseline group combined those with an unlikely or unknown exposure; ${ }^{16}$ the "possibly" exposed were excluded in order to compare clearly defined groups of exposed and unexposed. ORs were calculated for each occupational group at the "definite" level of exposure by time point, parent, and diagnostic group. All statistical analyses were conducted using STATA (version 6.0, StataCorp, 1984-97).

To avoid the over interpretation of chance associations, it was agreed a priori that only those statistically significant associations based on at least five exposed cases or controls were to be discussed. No results are presented for two occupational groups (fishing and tobacco dust) because of the small number of exposed subjects.

Additional analyses were conducted: (1) with adjustment for social class using an areal measure of "deprivation" (seven levels) derived from 1991 national census data and based on the place of residence at the time of diagnosis; ${ }^{5}(2)$ with the exclusion of surrogate occupational history data; and (3) using individually matched sets. Overall the results of these analyses did not deviate from those presented here (data not shown).

\section{RESULTS}

Table 1 summarises the numbers of mothers and fathers contributing to the analysis. Similar proportions of case $(54 \%)$ and control (56\%) mothers and case $(82 \%)$ and control $(82 \%)$ fathers reported being in work at periconception.

Table 2 presents the results for the occupational groups at periconception reporting the prior hypotheses from the study at the top of the table followed by the remaining analyses. Table 3 summarises the occupational groups for which statistically significant associations occurred at periconception and/or diagnosis.

The following sections describe the statistically significant raised risks more fully.

\section{Dermal (skin/epidermal) hydrocarbons}

Twofold increases in risk were seen for leukaemia and ALL among the children of mothers exposed to dermal (skin/ epidermal) hydrocarbons at periconception (leukaemia: OR $2.20,95 \%$ CI 1.23 to 3.95 ; ALL: OR 2.16, $95 \%$ CI 1.16 to 4.02 ). No increased risk was observed for exposures at diagnosis (leukaemia: OR 1.06, 95\% CI 0.35 to 3.14; ALL: OR 0.94, 95\% CI 0.27 to 3.22). Of the 17 leukaemia case mothers exposed at periconception, 10 had jobs allied to the printing trade, six were "metal process operatives", and one was a "motor mechanic".

\section{Exhaust fumes/driving/inhaled particulate hydrocarbons}

There is substantial overlap between the occupations classified as "exposed" to exhaust fumes, driving, and inhaled particulate hydrocarbons; therefore parents with certain jobs may be exposed to more than one of these agents and are, hence, included in more than one analysis. Table 4 details the overlap for jobs held at periconception by fathers of children with leukaemia. Of the 185 case and 618 control fathers, $92(50 \%)$ and 271 (44\%) respectively were in all three occupational groups, predominately employed as drivers of lorries, cars, taxis, and goods vehicles.

Among fathers for all three of these occupational exposures at periconception, small but statistically significantly increased risks were seen for childhood leukaemia and ALL (table 2). At diagnosis, the risk of leukaemia for exhaust fumes was statistically significant (OR $1.23,95 \%$ CI 1.00 to $1.52)$, whereas raised but non-statistically significant risks were present for driving (OR 1.14, 95\% CI 0.90 to 1.45 ) and inhaled particulate hydrocarbons (OR 1.14, 95\% CI 0.89 to 1.72). A similar pattern was observed for childhood ALL and exposures at diagnosis (exhaust fumes: OR 1.19, 95\% CI 0.95 to 1.49 ; driving: OR $1.10,95 \%$ CI 0.85 to 1.41 ; inhaled particulate hydrocarbons: OR $1.08,95 \%$ CI 0.82 to 1.42 ).

\section{Leather workers}

Statistically significant raised risks were seen for other cancers among the children of men working with leather at periconception (OR 4.02, 95\% CI 1.39 to 11.63 ) and diagnosis (OR 5.50, 95\% CI 1.10 to 27.38). Of the six case fathers classified as leather workers at periconception, three had children diagnosed with neuroblastoma, one with Wilms' tumour, one with retinoblastoma, and one with rhabdomyosarcoma. All case fathers had jobs classified as "shoe repairers, leather cutters and sewers, footwear lasters, makers and finishers, other leather making and repairing".

\section{Metal}

Statistically significant threefold increases in risk were present for children diagnosed with leukaemia and ALL whose mothers had been exposed to metal at periconception (leukaemia: OR 3.68, 95\% CI 1.59 to 8.55; ALL: OR 3.91, 95\% CI 1.64 to 9.32 ) but not at diagnosis (leukaemia: OR 2.54, 95\% CI 0.46 to 13.93; ALL: OR 1.58, 95\% CI 0.18 to 14.27 ). The majority of case mothers $(7 / 10)$ in this category were "machine tool, press stamping, and automatic machine operatives". There is overlap between this occupational group and occupational exposure to dermal (skin/epidermal) hydrocarbons with seven leukaemia case mothers and six control mothers being included in both analyses.

\section{Textile dust}

Statistically significant raised risks were observed for other cancers among the offspring of mothers and fathers exposed

Table 1 Number and proportion (\%) of mothers and fathers included in the analysis of periconceptual exposure

\begin{tabular}{|c|c|c|c|c|c|c|c|c|}
\hline & \multicolumn{4}{|c|}{ Mothers } & \multicolumn{4}{|c|}{ Fathers } \\
\hline & \multicolumn{2}{|c|}{ Cases $(n=3838)$} & \multicolumn{2}{|c|}{ Controls $(n=7629)$} & \multicolumn{2}{|c|}{ Cases $(n=3838$ ) } & \multicolumn{2}{|c|}{ Controls $(n=7629)$} \\
\hline & $n$ & $\%$ & $\mathbf{n}$ & $\%$ & $\mathbf{n}$ & $\%$ & $\mathbf{n}$ & $\%$ \\
\hline Parental interviews* & 3866 & 100 & 7657 & 100 & 3791 & 100 & 7308 & 100 \\
\hline Non-natural parent & 48 & 1.2 & 57 & 0.7 & 195 & 5.1 & 298 & 4.1 \\
\hline Included in analysis $†$ & 3818 & 98.8 & 7600 & 99.3 & 3596 & 94.9 & 7010 & 95.9 \\
\hline Reported job at periconception & 2091 & 54.1 & 4306 & 56.2 & 3088 & 81.5 & 5980 & 81.8 \\
\hline
\end{tabular}

*For each child enrolled in the study up to four parents (biological and non-biological) were interviewed.

†Parents without a job history are included in the analysis as "not exposed"; non-natural parents are excluded. 
Table 2 Number of exposed subjects (cases/controls), odds ratios (OR)t, and $95 \%$ confidence intervals (Cl) for mothers' and fathers' occupational groups at periconception

\begin{tabular}{|c|c|c|c|c|c|c|c|}
\hline \multirow[b]{2}{*}{ Occupational groups } & \multirow[b]{2}{*}{ Diagnostic group } & \multicolumn{3}{|l|}{ Mothers } & \multicolumn{3}{|l|}{ Fathers } \\
\hline & & Cases/controls & OR & $(95 \% \mathrm{Cl})$ & Cases/controls & OR & $(95 \% \mathrm{Cl})$ \\
\hline \multicolumn{8}{|l|}{ lonising radiation } \\
\hline lonising radiation & Leukaemia & $1 / 7$ & 0.63 & (0.08 to 5.15$)$ & $3 / 13$ & 1.03 & $(0.29$ to 3.65$)$ \\
\hline & AlL & $1 / 7$ & 0.76 & $(0.09$ to 6.19$)$ & $3 / 13$ & 1.25 & $(0.35$ to 4.40$)$ \\
\hline & CNS§ & $1 / 7$ & 1.53 & (0.19 to 12.40$)$ & $1 / 13$ & 0.82 & $(0.11$ to 6.32$)$ \\
\hline & Other $\Phi$ & $0 / 7$ & - & & $3 / 13$ & 1.18 & $(0.34$ to 4.19$)$ \\
\hline Chemicals & & & & & & & \\
\hline Agrochemicals & Leukaemia & $5 / 27$ & 0.81 & (0.31 to 2.12 ) & $36 / 185$ & 0.83 & (0.58 to 1.19 ) \\
\hline & AlL $\ddagger$ & $5 / 27$ & 0.97 & (0.37 to 2.52 ) & $31 / 185$ & 0.85 & (0.58 to 1.24$)$ \\
\hline & CNS§ & $3 / 27$ & 1.26 & (0.38 to 4.17 ) & $13 / 185$ & 0.77 & $(0.44$ to 1.36$)$ \\
\hline & Other & $5 / 27$ & 1.02 & (0.39 to 2.65 ) & $33 / 185$ & 0.91 & (0.64 to 1.36 ) \\
\hline Dermal hydrocarbonst† & Leukaemia & $17 / 35$ & 2.20 & $(1.23 \text { to } 3.95)^{\star *}$ & $104 / 479$ & 0.94 & (0.76 to 1.18 ) \\
\hline & AlL $\ddagger$ & $14 / 35$ & 2.16 & $(1.16 \text { to } 4.02)^{*}$ & $88 / 479$ & 0.96 & $(0.76$ to 1.21$)$ \\
\hline & CNS§ & $6 / 35$ & 1.85 & $(0.77$ to 4.41$)$ & $46 / 479$ & 1.03 & $(0.75$ to 1.41$)$ \\
\hline & Other & $8 / 35$ & 1.23 & $(0.57$ to 2.66$)$ & $74 / 479$ & 0.80 & (0.62 to 1.03 ) \\
\hline Driving & Leukaemia & $5 / 14$ & 1.48 & (0.53 to 4.13 ) & $121 / 389$ & 1.36 & $(1.10 \text { to } 1.68)^{* *}$ \\
\hline & AlLł & $5 / 14$ & 1.74 & (0.63 to 4.85 ) & $95 / 389$ & 1.26 & $(1.00 \text { to } 1.59)^{*}$ \\
\hline & CNS§ & $1 / 14$ & 0.85 & $(0.11$ to 6.50$)$ & $36 / 389$ & 1.04 & $(0.73$ to 1.48$)$ \\
\hline & Other & 0 & - & & $83 / 389$ & 1.11 & (0.87 to 1.42 ) \\
\hline Exhaust fumes & Leukaemia & $9 / 25$ & 1.58 & (0.74 to 3.40$)$ & $147 / 485$ & 1.33 & $(1.09 \text { to } 1.61)^{* *}$ \\
\hline & ALL‡ & $8 / 25$ & 1.68 & (0.76 to 3.74$)$ & $118 / 485$ & 1.26 & $(1.02 \text { to } 1.56)^{*}$ \\
\hline & CNS§ & $3 / 25$ & 1.33 & (0.40 to 4.42$)$ & $47 / 485$ & 1.08 & $(0.79$ to 1.47$)$ \\
\hline & Other & $2 / 25$ & 0.43 & (0.10 to 1.82$)$ & $103 / 485$ & 1.13 & $(0.90$ to 1.41$)$ \\
\hline Inhaled particulate hydrocarbons & Leukaemia & $6 / 12$ & 2.28 & (0.85 to 6.08$)$ & $115 / 345$ & 1.48 & $(1.19 \text { to } 1.84)^{* * *}$ \\
\hline & AlL & $5 / 12$ & 2.26 & $(0.79$ to 6.45$)$ & $93 / 345$ & 1.41 & $(1.11 \text { to } 1.79)^{* *}$ \\
\hline & CNS§ & $2 / 12$ & 1.77 & (0.39 to 7.93 ) & $35 / 345$ & 1.13 & $(0.79$ to 1.61$)$ \\
\hline & Other & 0 & - & & $71 / 345$ & 1.09 & (0.84 to 1.42 ) \\
\hline Solvents & Leukaemia & $36 / 142$ & 1.13 & (0.78 to 1.64$)$ & $78 / 315$ & 1.07 & (0.83 to 1.37$)$ \\
\hline & ALL & $27 / 142$ & 1.00 & $(0.66$ to 1.51$)$ & $64 / 315$ & 1.05 & $(0.79$ to 1.37$)$ \\
\hline & CNS§ & $16 / 142$ & 1.23 & (0.73 to 2.07 ) & $30 / 315$ & 1.04 & $(0.73$ to 1.57$)$ \\
\hline & Other & $31 / 142$ & 1.19 & (0.81 to 1.77$)$ & $69 / 315$ & 1.15 & (0.87 to 1.50$)$ \\
\hline Other occupational groups & & & & & & & \\
\hline Agriculture & Leukaemia & $7 / 22$ & 1.41 & (0.60 to 3.31$)$ & $29 / 140$ & 0.90 & (0.60 to 1.34$)$ \\
\hline & ALL $\ddagger$ & $7 / 22$ & 1.68 & $(0.72$ to 3.95$)$ & $25 / 140$ & 0.92 & $(0.59$ to 1.40$)$ \\
\hline & CNS§ & $3 / 22$ & 1.55 & $(0.46$ to 5.19$)$ & $9 / 140$ & 0.70 & (0.35 to 1.38 ) \\
\hline & Other & $5 / 22$ & 1.24 & $(0.47$ to 3.29$)$ & $24 / 140$ & 0.90 & (0.58 to 1.39 ) \\
\hline Animals & Leukaemia & $3 / 11$ & 1.14 & (0.32 to 4.11$)$ & $13 / 56$ & 1.00 & $(0.54$ to 1.80$)$ \\
\hline & AlLł & $2 / 11$ & 0.90 & (0.20 to 4.08$)$ & $12 / 56$ & 1.09 & $(0.57$ to 2.00$)$ \\
\hline & CNS§ & $0 / 11$ & - & & $2 / 56$ & 0.40 & $(0.10$ to 1.64$)$ \\
\hline & Other & $1 / 11$ & 0.51 & (0.07 to 3.92$)$ & $8 / 56$ & 0.75 & $(0.35$ to 1.56$)$ \\
\hline Ceramics/glass & Leukaemia & $3 / 8$ & 1.68 & (0.45 to 6.37$)$ & $7 / 15$ & 2.19 & (0.84 to 5.05 ) \\
\hline & ALL $\ddagger$ & $2 / 8$ & 1.29 & $(0.27$ to 6.10$)$ & $4 / 15$ & 1.51 & $(0.47$ to 4.27$)$ \\
\hline & CNS§ & $0 / 8$ & - & & $3 / 15$ & 2.35 & (0.63 to 7.55$)$ \\
\hline & Other & $3 / 8$ & 1.97 & $(0.52$ to 7.46$)$ & $4 / 15$ & 1.46 & $(0.46$ to 4.16$)$ \\
\hline Coal dust & Leukaemia & $0 / 0$ & - & & $10 / 32$ & 1.38 & (0.68 to 2.82 ) \\
\hline & ALL‡ & $0 / 0$ & - & & $9 / 32$ & 1.50 & $(0.71$ to 3.15$)$ \\
\hline & CNS§ & $0 / 0$ & - & & $1 / 32$ & 0.33 & (0.05 to 2.45 ) \\
\hline & Other & $0 / 0$ & - & & $5 / 32$ & 0.79 & $(0.31$ to 2.05$)$ \\
\hline Construction & Leukaemia & $0 / 1$ & - & & $89 / 340$ & 1.14 & (0.88 to 1.43 ) \\
\hline & AlL‡ & $0 / 1$ & - & & $72 / 340$ & 1.09 & (0.82 to 1.39 ) \\
\hline & CNS§ & $0 / 1$ & - & & $30 / 340$ & 0.92 & (0.67 to 1.43 ) \\
\hline & Other & $1 / 1$ & 6.28 & $(0.39$ to 100$)$ & $77 / 340$ & 1.20 & (0.94 to 1.57 ) \\
\hline Electromagnetic fields & Leukaemia & $86 / 452$ & 0.83 & $(0.66$ to 1.06$)$ & $108 / 374$ & 1.23 & $(1.00$ to 1.55$)$ \\
\hline & ALL & $74 / 452$ & 0.85 & $(0.66$ to 1.10$)$ & $87 / 374$ & 1.16 & $(0.93$ to 1.50$)$ \\
\hline & CNS§ & $39 / 452$ & 0.95 & (0.67 to 1.32 ) & $35 / 374$ & 1.04 & $(0.72$ to 1.47$)$ \\
\hline & Other & $72 / 452$ & 0.85 & $(0.66$ to 1.10$)$ & $71 / 374$ & 1.00 & $(0.78$ to 1.31$)$ \\
\hline Increased temperature & Leukaemia & $0 / 0$ & - & & $2 / 8$ & 1.07 & $(0.23$ to 5.04$)$ \\
\hline & ALL & $0 / 0$ & - & & $2 / 8$ & 1.27 & $(0.27$ to 5.97$)$ \\
\hline & CNS§ & $0 / 0$ & - & & $1 / 8$ & 1.42 & (0.18 to 11.45 ) \\
\hline & Other & $1 / 0$ & - & & $2 / 8$ & 1.30 & $(0.28$ to 6.20$)$ \\
\hline Leather workers & Leukaemia & $4 / 13$ & 1.43 & (0.46 to 4.39 ) & $2 / 8$ & 1.04 & (0.22 to 4.92$)$ \\
\hline & AlL & $3 / 13$ & 1.31 & (0.37 to 4.63 ) & $2 / 8$ & 1.23 & $(0.26$ to 5.80$)$ \\
\hline & CNS§ & $1 / 13$ & 0.75 & $(0.10$ to 5.78$)$ & 0 & - & \\
\hline & Other & $2 / 13$ & 0.82 & $(0.19$ to 3.65$)$ & $6 / 8$ & 4.02 & $(1.39 \text { to } 11.63)^{* *}$ \\
\hline Medical/health care & Leukaemia & $85 / 465$ & 0.78 & $(0.61 \text { to } 0.98)^{*}$ & $19 / 118$ & 0.70 & $(0.43$ to 1.14$)$ \\
\hline & ALL† & $73 / 465$ & 0.79 & $(0.61$ to 1.02$)$ & $15 / 118$ & 0.66 & (0.38 to 1.13 ) \\
\hline & CNS§ & $32 / 465$ & 0.77 & (0.53 to 1.12 ) & $10 / 118$ & 0.93 & $(0.49$ to 1.79$)$ \\
\hline & Other & $73 / 465$ & 0.85 & $(0.66$ to 1.10$)$ & $27 / 118$ & 1.22 & $(0.80$ to 1.86$)$ \\
\hline Metal & Leukaemia & $10 / 12$ & 3.68 & $(1.59 \text { to } 8.55)^{* *}$ & $147 / 690$ & 0.91 & $(0.76$ to 1.10$)$ \\
\hline & ALL‡ & $9 / 12$ & 3.91 & $(1.64 \text { to } 9.32)^{* *}$ & $127 / 690$ & 0.95 & $(0.78$ to 1.16$)$ \\
\hline & CNS§ & $2 / 12$ & 1.80 & $(0.40$ to 8.11$)$ & $67 / 690$ & 1.07 & $(0.82$ to 1.40$)$ \\
\hline & Other & $4 / 12$ & 1.79 & (0.58 to 5.58 ) & $120 / 690$ & 0.89 & $(0.72$ to 1.09$)$ \\
\hline Metal (acid mists) & Leukaemia & $0 / 0$ & - & & $3 / 5$ & 3.19 & (0.62 to 10.95 ) \\
\hline & ALL‡ & $0 / 0$ & - & & $3 / 5$ & 3.80 & (0.74 to 13.09 ) \\
\hline & CNS§ & $0 / 0$ & - & & $1 / 5$ & 2.80 & (0.25 to 18.24$)$ \\
\hline & Other & $0 / 0$ & - & & $4 / 5$ & 3.90 & (1.13 to 15.82 ) \\
\hline Metal fumes & Leukaemia & $0 / 3$ & - & & $16 / 93$ & 0.73 & $(0.43$ to 1.24$)$ \\
\hline & ALL & $0 / 3$ & - & & $14 / 93$ & 0.76 & (0.43 to 1.33 ) \\
\hline & CNS§ & $1 / 3$ & 3.55 & (0.37 to 34.21$)$ & $9 / 93$ & 1.08 & (0.54 to 2.15 ) \\
\hline & Other & $0 / 3$ & - & & $11 / 93$ & 0.63 & (0.34 to 1.18 ) \\
\hline
\end{tabular}




\begin{tabular}{|c|c|c|c|c|c|c|c|}
\hline Occupational groups & Diagnostic group & Cases/controls & OR & $(95 \% \mathrm{Cl})$ & Cases/controls & OR & $(95 \% \mathrm{Cl})$ \\
\hline \multirow{4}{*}{ Metal working (oil mists) } & Leukaemia & $0 / 0$ & - & & $10 / 51$ & 0.86 & $(0.43$ to 1.67$)$ \\
\hline & AlL & $0 / 0$ & - & & $9 / 51$ & 0.92 & $(0.44$ to 1.84$)$ \\
\hline & CNS§ & $0 / 0$ & - & & $8 / 51$ & 1.82 & $(0.85$ to 3.80$)$ \\
\hline & Other & $0 / 0$ & - & & $5 / 51$ & 0.51 & $(0.20$ to 1.27$)$ \\
\hline \multirow[t]{4}{*}{ Mining } & Leukaemia & $0 / 0$ & - & & $12 / 38$ & 1.48 & $(0.73$ to 2.69$)$ \\
\hline & ALL & $0 / 0$ & - & & $10 / 38$ & 1.50 & (0.70 to 2.84 ) \\
\hline & CNS§ & $0 / 0$ & - & & $1 / 38$ & 0.30 & $(0.04$ to 2.05$)$ \\
\hline & Other & $0 / 0$ & - & & $7 / 38$ & 0.98 & (0.24 to 2.11$)$ \\
\hline \multirow{4}{*}{ Outdoor workers } & Leukaemia & $6 / 26$ & 1.01 & (0.42 to 2.48 ) & $100 / 427$ & 1.01 & $(0.80$ to 1.25$)$ \\
\hline & ALL & $5 / 26$ & 1.01 & $(0.39$ to 2.63 ) & $80 / 427$ & 0.96 & (0.74 to 1.21 ) \\
\hline & CNS§ & $5 / 26$ & 2.15 & $(0.82$ to 5.59$)$ & $36 / 427$ & 0.94 & (0.69 to 1.38$)$ \\
\hline & Other & $8 / 26$ & 1.70 & $(0.77$ to 3.77 ) & $86 / 427$ & 1.06 & $(0.85$ to 1.37$)$ \\
\hline \multirow{4}{*}{ Paints } & Leukaemia & $0 / 0$ & - & & $25 / 91$ & 1.22 & $(0.76$ to 1.85$)$ \\
\hline & ALL & $0 / 0$ & - & & $21 / 91$ & 1.22 & $(0.73$ to 1.91$)$ \\
\hline & CNS§ & $0 / 0$ & - & & $12 / 91$ & 1.50 & $(0.79$ to 2.66$)$ \\
\hline & Other & $0 / 0$ & - & & $22 / 91$ & 1.33 & $(0.80$ to 2.06$)$ \\
\hline \multirow{4}{*}{ Paper production } & Leukaemia & $0 / 0$ & - & & $0 / 2$ & - & \\
\hline & ALL & $0 / 0$ & - & & $0 / 2$ & - & \\
\hline & CNS§ & $0 / 0$ & - & & $1 / 2$ & 4.85 & (0.44 to 53.72 ) \\
\hline & Other & $0 / 0$ & - & & $0 / 2$ & - & \\
\hline \multirow[t]{4}{*}{ Plastic } & Leukaemia & $3 / 5$ & 2.75 & (0.66 to 11.56$)$ & $7 / 16$ & 1.83 & (0.75 to 4.44 ) \\
\hline & ALL & $3 / 5$ & 3.26 & $(0.78$ to 13.75$)$ & $5 / 16$ & 1.52 & (0.55 to 4.14 ) \\
\hline & CNS§ & $0 / 5$ & - & & $1 / 16$ & 0.73 & $(0.10$ to 5.57$)$ \\
\hline & Other & $0 / 5$ & - & & $3 / 16$ & 1.02 & $(0.30$ to 3.53$)$ \\
\hline \multirow[t]{4}{*}{ Printing } & Leukaemia & $10 / 29$ & 1.58 & (0.77 to 3.27 ) & $13 / 65$ & 0.87 & $(0.48$ to 1.59 ) \\
\hline & ALL & $7 / 29$ & 1.32 & $(0.58$ to 3.03 ) & $10 / 65$ & 0.81 & $(0.41$ to 1.57$)$ \\
\hline & CNS§ & $5 / 29$ & 1.83 & (0.70 to 4.72 ) & $6 / 65$ & 0.84 & (0.44 to 2.35 ) \\
\hline & Other & $4 / 29$ & 0.74 & $(0.26$ to 2.10$)$ & $10 / 65$ & 0.79 & $(0.41$ to 1.56$)$ \\
\hline \multirow[t]{4}{*}{ Rubber manufacture } & Leukaemia & $0 / 0$ & - & & $4 / 4$ & 4.12 & $(1.03 \text { to } 16.51)^{*}$ \\
\hline & ALL & $0 / 0$ & - & & $4 / 4$ & 4.80 & $(1.20 \text { to } 19.28)^{*}$ \\
\hline & CNS§ & $0 / 0$ & - & & $0 / 4$ & - & \\
\hline & Other & $1 / 0$ & - & & $0 / 4$ & - & \\
\hline \multirow[t]{4}{*}{ Textile dust } & Leukaemia & $36 / 136$ & 1.17 & (0.80 to 1.69 ) & $11 / 58$ & 0.83 & (0.43 to 1.58 ) \\
\hline & ALL & $31 / 136$ & 1.20 & $(0.81$ to 1.78$)$ & $9 / 58$ & 0.81 & $(0.40$ to 1.64$)$ \\
\hline & CNS§ & $11 / 136$ & 0.89 & $(0.48$ to 1.65$)$ & $4 / 58$ & 0.72 & $(0.26$ to 2.00$)$ \\
\hline & Other & $45 / 136$ & 1.81 & $(1.28 \text { to } 2.55)^{* * *}$ & $22 / 58$ & 2.02 & $(1.23 \text { to } 3.31)^{* *}$ \\
\hline \multirow[t]{4}{*}{ Wood dust } & Leukaemia & $1 / 2$ & 2.21 & (0.20 to 24.49 ) & $42 / 161$ & 1.08 & $(0.77$ to 1.54$)$ \\
\hline & ALL & $1 / 2$ & 2.68 & $(0.24$ to 29.74$)$ & $35 / 161$ & 1.10 & $(0.76$ to 1.60$)$ \\
\hline & CNS§ & 0 & - & & $8 / 161$ & 0.46 & $(0.22 \text { to } 0.99)^{*}$ \\
\hline & Other & $1 / 2$ & 2.74 & (0.25 to 30.37$)$ & $38 / 161$ & 1.27 & $(0.89$ to 1.82$)$ \\
\hline \multicolumn{8}{|c|}{$\begin{array}{l}\text { tUnmatched analysis using all controls with adjustment for single year of age, sex, and region of residence. } \\
\text { tAcute lymphoblastic leukaemia. } \\
\text { sCentral nervous system tumours. } \\
\text { 'Excludes leukaemia and CNS tumours. } \\
++ \text { Skin/epidermal exposure to hydrocarbons. } \\
{ }^{*} \mathrm{p}<0.05,{ }^{, *} p<0.01,{ }^{* * *} \mathrm{p}<0.001 \text {. }\end{array}$} \\
\hline
\end{tabular}

to textile dust at periconception (mothers: OR 1.81, 95\% CI 1.28 to 2.55 ; fathers: OR $2.02,95 \%$ CI 1.23 to 3.31 ). These risks were raised but not statistically significantly so at diagnosis (mothers: OR 1.15, 95\% CI 0.58 to 2.28; fathers: OR $1.62,95 \%$ CI 0.82 to 3.18 ). The children of the 22 case fathers and 45 case mothers exposed at periconception were diagnosed with a wide range of solid tumours. Of note, were seven cases of Hodgkin's disease (HD) in the offspring of exposed case mothers, which over represented this tumour $(15.6 \%, 7 / 45)$ compared to the distribution in the entire set of cases $(8 \%, 117 / 1414)$. The majority of mothers of exposed cases $(76 \%)$ and controls $(67 \%)$ were classed as "sewing machinists, menders, darners, and embroiderers".

\section{DISCUSSION}

At the outset of the UKCCS, specific aetiological hypotheses were proposed for factors within this investigation: namely, childhood cancer may be caused by exposure to ionising radiation or hazardous chemicals, either of the child during pregnancy or by exposure of the parental germ cells before the child's conception. This paper presents the results for parental occupational exposures at periconception (in general, statistically significant excesses/deficits associated with exposure at periconception were also present for exposures at birth). The a priori hypotheses are considered first and the statistically significant associations are reported and discussed in the context of the published literature and their plausibility.

\section{lonising radiation}

No increased risk of any type of childhood cancer was associated with parental periconception occupational exposure to ionising radiation. The findings fail to support the paternal preconception irradiation hypothesis suggested by Gardner and colleagues, ${ }^{19}$ but are consistent with those of Draper and colleagues, ${ }^{20}$ Roman and colleagues, ${ }^{21}$ and Doll and colleagues. ${ }^{22}$

\section{Chemicals}

No association with leukaemia following paternal exposure to solvents ${ }^{23}$ was observed.

No links were found between any type of childhood cancer and parental exposure to agriculture, agrochemicals or animals. This is not consistent with a review of epidemiological studies of pesticides and childhood cancer, ${ }^{3}$ which concluded that a role for pesticide exposure in the development of childhood cancer was plausible. Risks for exposure to "agriculture", covering farm life and animal exposures, and childhood CNS tumours have been reviewed, ${ }^{24}$ showing few consistent associations, while a recent study by Cordier and 
Table 3 Summary of the parental occupational groups held at periconception and/or diagnosis associated with a statistically significant excess (normal font) or deficit (italics) of childhood cancer

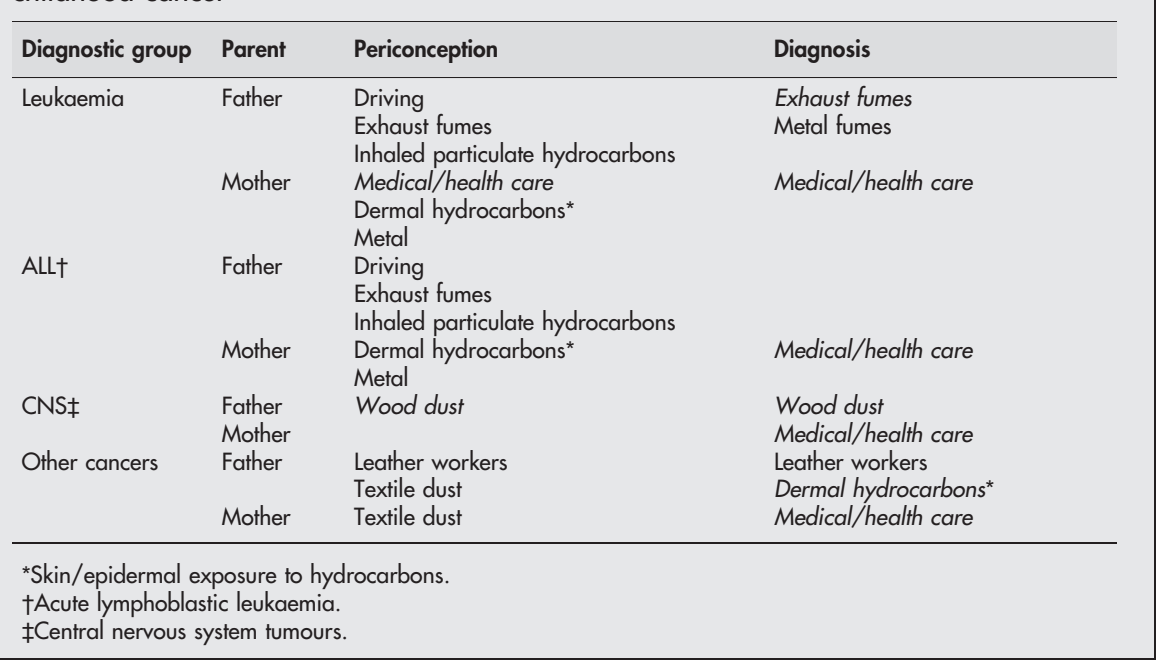

colleagues ${ }^{25}$ reported an association between parental work in agriculture prior to the child's birth and CNS tumours. The suggestion of increased risk of Wilms' tumour in the offspring of fathers exposed to pesticides ${ }^{11}$ is not specifically addressed in the present data.

Paternal exposure at periconception to exhaust fumes, driving, or inhaled particulate hydrocarbons was associated with increases in the risk of childhood leukaemia and ALL but no other group of childhood cancers. These statistically significant raised risks were not present for mothers and generally were not present at diagnosis, suggesting that the route of these exogenous exposures may be via a direct effect on the developing sperm. ${ }^{4}$ The results from the UKCCS for paternal occupational exposure at periconception to exhaust fumes for childhood leukaemia were compared with findings taken from all the published epidemiological studies of childhood haematological malignancies and parental occupation where the exposure and time windows were broadly comparable. ${ }^{26-45}$ For example, definitions of exposure ranged from motor vehicle drivers to hydrocarbons and time of exposure from "before conception" to "birth". Three additional studies were identified but excluded from this comparison as the paternal occupational exposures considered were held at either the child's death ${ }^{13}{ }^{46}$ or anytime during the father's life. ${ }^{47}$ Figure 1 shows the odds ratios from each study plotted as a grey box, the area of which is proportional to the amount of statistical information for that particular estimate, with the vertical line representing the null value (that is, OR 1). The area of the box and width of the $95 \%$ confidence intervals, represented as horizontal lines, reflect the reliability of the point estimate. Excluding the study of Olsen and colleagues, ${ }^{40}$ for which confidence intervals were unavailable, the pooled OR for 20 studies was 1.21 (95\% CI 1.11 to 1.32 ) using a fixed effects model. Although statistically significant, this estimate must be interpreted with caution because none of the studies used common definitions of exposure or diagnosis, so whether this represents a "real" effect requires further investigation.

There is some tentative biological plausibility to the risks for exposure to traffic related emissions that are known to

Table 4 Number of fathers of children with leukaemia and their unmatched controls with occupational exposure to exhaust fumes, driving, and inhaled particulate hydrocarbons at periconception

\begin{tabular}{|c|c|c|c|c|c|c|}
\hline \multirow[b]{2}{*}{ Occupational group } & \multicolumn{2}{|c|}{ Cases } & \multicolumn{2}{|c|}{ Controls } & \multirow[b]{2}{*}{ No. jobs } & \multirow[b]{2}{*}{ Job titles } \\
\hline & $\mathbf{n}$ & $\%$ & $\mathbf{n}$ & $\%$ & & \\
\hline Exhaust fumes only & 41 & 22 & 155 & 25 & 7 & $\begin{array}{l}\text { Garage managers and proprietors; motor mechanics } \\
\text { and auto-engineers; traffic wardens; bus inspectors; } \\
\text { refuse and salvage collectors; driver's mates; } \\
\text { messengers }\end{array}$ \\
\hline Driving only & 19 & 10 & 77 & 12 & 4 & $\begin{array}{l}\text { Crane drivers; mechanical plant drivers and } \\
\text { operatives; fork lift truck drivers; rail engine drivers } \\
\text { and assistants }\end{array}$ \\
\hline Inhaled particulate hydrocarbons only & 19 & 10 & 56 & 9 & 6 & $\begin{array}{l}\text { Fire service officers; furnace operatives (metal); coal } \\
\text { mine labourers; smith and forge workers; labourers in } \\
\text { foundries; moulders, core makers and die casters }\end{array}$ \\
\hline Exhaust fumes and driving & 10 & 5 & 41 & 7 & 3 & $\begin{array}{l}\text { Driving instructors; roundsmen and van salespersons; } \\
\text { agricultural machinery drivers and operatives }\end{array}$ \\
\hline $\begin{array}{l}\text { Exhaust fumes and inhaled particulate } \\
\text { hydrocarbons }\end{array}$ & 4 & 2 & 18 & 3 & 3 & $\begin{array}{l}\text { Tyre and exhaust fitters; petrol pump forecourt } \\
\text { attendants; bus conductors }\end{array}$ \\
\hline $\begin{array}{l}\text { Exhaust fumes, driving, and inhaled } \\
\text { particulate hydrocarbons }\end{array}$ & 92 & 50 & 271 & 44 & 3 & $\begin{array}{l}\text { Drivers of road goods vehicles; bus and coach } \\
\text { drivers; taxi, cab drivers and chauffeurs }\end{array}$ \\
\hline Total & 185 & & 618 & & & \\
\hline
\end{tabular}


contain both suspected and confirmed carcinogens, including benzene (a known leukemogen at high levels of exposure) ${ }^{48}{ }^{49}$ Ninety four per cent of benzene emissions come from petrol evaporation and petrol/diesel vehicle exhaust. ${ }^{50}$ An explanation for the UKCCS findings, which show putative adverse effects of fathers' occupational exposure to traffic pollution, would require the developing sperm to be affected. Although not mutagenic, benzene forms phenolic metabolites in the liver that together have the capacity to induce DNA damage such as strand breaks, mitotic combinations, translocations, or aneuploidy. ${ }^{51}$ In addition, the metabolism of benzene may produce oxidative stress within cells, which could result in DNA damage. ${ }^{52}$ The potential adverse health effects in children from exposure of their fathers to traffic related air pollution around the time of conception are not a published area of research. The suggestion that children themselves exposed to high densities of traffic may be at increased risk of leukaemia ${ }^{53} 54$ was not confirmed by a recent large scale study in Denmark. ${ }^{55}$

Causal interpretation of the UKCCS finding is tempered by inconsistencies in the literature, the low, albeit, statistically significant ORs, the heterogeneity of the exposure, and the absence of a known biologically plausible mechanism. Many of the jobs in the three exposure groups are classed as "manual" and associated with lower socioeconomic groups. As the control parents participating in the UKCCS tended to be of a higher social class, ${ }^{5}$ manual jobs might be under represented in the control population, therefore increasing the likelihood of a positive association where manual jobs predominate. However, this situation is present for other groups (for example, construction workers) where no associations were observed.

\section{Other occupational groups}

No evidence was obtained of any association of CNS tumours with parental occupational exposure to electromagnetic fields or hydrocarbons (and related occupations). ${ }^{23} 25$

Threefold increased risks of leukaemia and ALL among the offspring of mothers exposed to metals were observed at periconception but not at diagnosis. Buckley and colleagues ${ }^{38}$ reported a statistically significant increased risk associated with childhood acute non-lymphoblastic leukaemia and maternal exposure to metals before pregnancy; however, studies examining other types of leukaemia have not shown such associations. ${ }^{374456}$ This occupational group overlaps considerably with the dermal (skin/epidermal) hydrocarbon group, with $70 \%$ of the leukaemia case mothers from the metal group also contributing to the positive association seen for dermal exposure to hydrocarbons. This illustrates the difficulty of disentangling these findings with respect to identifying a single exposure. It seems unlikely that maternal exposure to dermal hydrocarbons represents a real risk, as the mechanism by which these agents affect the ova via skin absorption is unclear. For inhaled particulate hydrocarbons, where the dose is likely to be higher, the risk is nonstatistically significantly raised. The minimal numbers of mothers of children with acute non-lymphoblastic leukaemia in either the metal or dermal hydrocarbons group precluded any specific investigation of this subtype and we were unable to confirm that metal exposure might be related to this type of leukaemia in children. ${ }^{23}$

The positive associations observed in the UKCCS for textile dust were unexpected. Increased risks were present for both parents for a range of paediatric cancers, most of which are likely to have differing aetiologies, making this a chance finding. The excess of children with HD whose mothers had been exposed was notable but finds no support in the published literature.

\section{Study design}

The limitations of this study are common to all analyses of occupational data from interview based case-control studies and include difficulties with defining "time windows" of exposure, ${ }^{57}$ different approaches to exposure assessment, and use of self reported information, all of which may explain the lack of consistency in published studies. Recall/reporting bias is an unlikely explanation for any of our findings, as particular occupations are not generally known to be associated with the risk of childhood cancer, and collecting information via a complete occupational history, which does not focus on any specific jobs, time periods, or specific chemicals or exposures (such as radiation), may have avoided over (or under) reporting by case parents. The overall proportion of parents reporting jobs at periconception was similar for cases and controls and there is no evidence to suggest more complete or precise reporting by case parents compared to controls. The proportion of surrogate information gathered on fathers was higher for controls than cases,

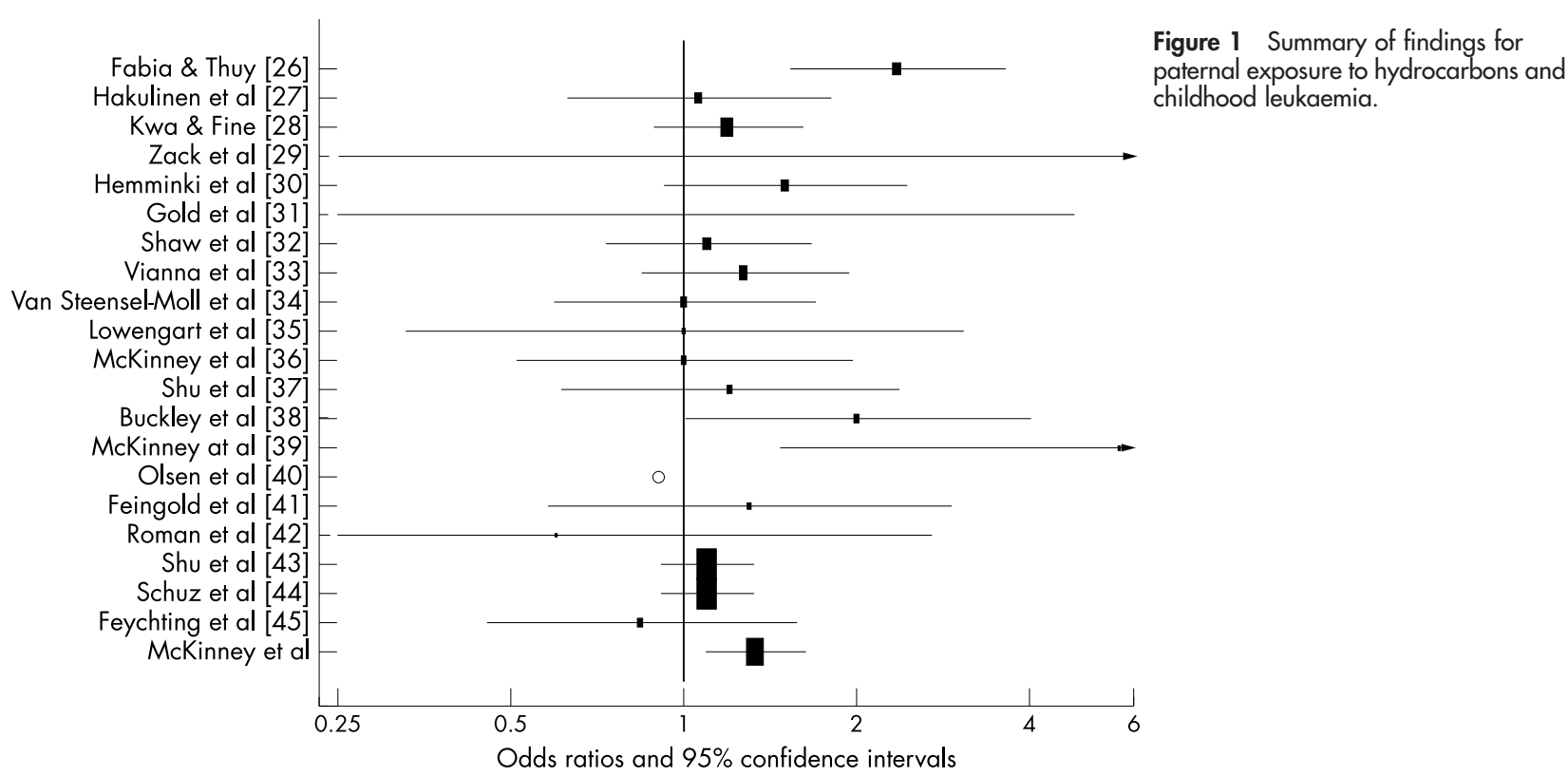


$24.3 \%$ versus $12.7 \%$ respectively, but removal of these data from the analyses did not alter the results (data not shown). The proxy data were mainly the reporting by wives of their husbands' occupational history, which could be considered relatively accurate.

Exposure assessment was facilitated by the aggregation of jobs into occupational groups-that is, combining jobs with defined common exposures. This approach has several advantages as it helps to overcome the problem of small numbers of exposed subjects in any single occupation as well as ensuring that jobs with similar exposures do not form part of the comparison group. This analysis compared distinct groups of definitely exposed and definitely unexposed individuals, excluding parents deemed to have possible exposure. However, combining different jobs into a unified group may misclassify exposure by putting together occupations with additional different exposures, ${ }^{58}$ those with multiple or mixed exposures, all of which may be of differing magnitudes and qualities. Our method of exposure assessment (allocating occupational groups) is based on the "likelihood" of exposure and only indirectly and rather crudely on the "level" of exposure, such as the intensity or frequency. This restriction may introduce misclassification of exposure, which would conventionally be interpreted as diluting the risk estimate towards unity, but this may not always be true. ${ }^{59}$

The accuracy of the coding of job titles was comparable with other studies and the duplicate coding exercise showed that even where different codes were allocated to the same job this rarely resulted in a change of classification of occupational group (data not shown).

The response rate for case parents in the study $(87 \%)$ was higher than for control parents (64\%) and overall these sets of parents differed with respect to socioeconomic group. ${ }^{60}$ The effect of this differential and potentially biased participation on the results presented here is impossible to quantify, although adjustment for area-based deprivation did not alter our findings (data not shown). The statistically significantly reduced risks seen for mothers in the medical/health care group may reflect recruitment bias as occupations in this group mainly fall into social class categories I and II.

The generation of risk estimates for 31 occupational groups for each parent, time period, and diagnostic group may have resulted in a number of statistically significant findings by chance. In these circumstances, it is important to interpret the results in relation to their level of statistical significance, magnitude of risk, timing of exposure, potential biological mechanisms, and previously published literature. ${ }^{61}$

In conclusion, the analysis of self reported parental occupational histories from this large population based case-control study has failed to produce any strong evidence to link occupational exposures of parents with an increased risk of childhood cancer. In particular, no effect of paternal exposure to ionising radiation and increased risk of childhood cancer was observed. The consistency of the associations observed in these data between childhood leukaemia and paternal occupational exposure to exhaust fumes, driving, and/or inhaled particulate hydrocarbons at periconception suggest a small risk for vehicle related exhaust but the data cannot support the identification of any specific chemicals. However, other explanations cannot be excluded and more detailed research into the nature of such an association is required.

\section{ACKNOWLEDGEMENTS}

The United Kingdom Childhood Cancer Study is sponsored and administered by the United Kingdom Coordinating Committee on Cancer Research and the Leukaemia Research Fund. The Study is conducted by 12 teams of investigators (ten clinical and epidemiological and two biological) based in university departments, research institutes, and the National Health Service in Scotland. The work is coordinated by a Management Committee and in Scotland by a Steering Group. It is supported by the UK Children's Cancer Study Group of paediatric oncologists and by the National Radiological Protection Board.

Financial support has been provided by the Cancer Research Campaign, the Imperial Cancer Research Fund, the Leukaemia Research Fund, and the Medical Research Council through grants to their units; by the Leukaemia Research Fund, the Department of Health, the Electricity Association, the Irish Electricity Supply Board (ESB), the National Grid Company plc, and Westlakes Research (Trading) Ltd through grants for the general expenses of the study; by the Kay Kendall Leukaemia Fund for the associated laboratories studies, and by the Foundation for Children with Leukaemia for the study of electric fields. The investigation in Scotland is funded principally by The Scottish Office, and by ScottishPower plc, Scottish Hydro-Electric plc, and Scottish Nuclear Ltd.

We should like to thank the members of the UK Childhood Cancer Study Group for their support, and staff of local hospitals, general practitioners, general practice staff, and UKCCS interviewers and technicians. We should especially like to thank the families of the children included in the study, without whom this investigation would not have been possible

We would also like to thank Brian Pannett (MRC Environmental Epidemiology Unit, University of Southampton) and Krys Baker (Cancer Research UK, Cancer Epidemiology Unit, University of Oxford) for help with the development of the occupational groups. UKCCS Investigators: KK Cheng* and E Gilman, Central region; NE Day*, J Skinner, and D Williams, East Anglia region; R Cartwright* and A Craft*, North East region; JM Birch* and OB Eden*, North West region; PA McKinney*, Scotland; J Deacon and J Peto*, South East region; $\mathrm{V}$ Beral* and E Roman*, South Midlands region; $\mathrm{P}$ Elwood*, South Wales region; FE Alexander* and M Mott, South West region; CED Chilvers* and K Muir, Trent region; NT Fear, G Law, E Roman*, and G Simpson, Leukaemia Research Fund Data Management Processing Group; R Doll*, Epidemiological Studies Unit, University of Oxford, Oxford; CM Taylor*, Immunogenetics Laboratory, University of Manchester, Manchester; M Greaves*, Leukaemia Research Fund Centre, Institute of Cancer Research.

Management committee: * UKCCS Investigators and D Goodhead, Radiation and Genome Stability Unit, Medical Research Council, Harwell; FA Fry, National Radiological Protection Board; G Adams, UK Coordinating Committee for Cancer Research.

\section{Authors' affiliations \\ P A McKinney, N T Fear, D Stockton, Information and Statistics Division of the CSA for NHS Scotland, Trinity Park House, Edinburgh, UK}

\section{REFERENCES}

1 Drever F, ed. Occupational health. Decennial supplement for England and Wales. Series DS no 10. London: HMSO, 1995.

2 Colt JS, Blair A. Parental occupational exposures and risk of childhood cancer. Environ Health Perspect 1998;106:909-25.

3 Zahm SH, Ward MH. Pesticides and childhood cancer. Environ Health Perspect 1998;106:893-908.

4 Davis DL, Friedler G, Mattison D, et al. Male-mediated teratogenesis and other reproductive effects: Biologic and epidemiologic findings and a plea for clinical research. Reprod Toxicol 1992;6:289-92.

5 UK Childhood Cancer Study Investigators. The United Kingdom Childhood Cancer Study: objectives, materials and methods. Br J Cancer 2000;82:1073-102.

6 Office of Population Censuses and Surveys. Standard occupational classification. Volume 1. London: HMSO, 1990.

7 Central Statistical Office. Standard industrial classification of economic activities 1992. London: HMSO, 1992.

8 Elias P, Halstead K, Prandy K. Computer assisted standard occupational coding. London: HMSO, 1993.

9 Campanelli P, Thomson K, Moon N, et al. Chapter 19. The quality of occupational coding in the United Kingdom. In: Lyberg LE, Biemer P, Collins M, et al, eds. Survey measurement and process quality. London: Wiley Interscience, 1997.

10 Office of Population Censuses and Surveys. Standard occupational classification. Volume 1. London: HMSO, 1970.

11 Fear NT. Paternal occupation and childhood cancer: An analysis of routinely collected death certification data. DPhil, Oxford, 1997.

12 Fear NT, Roman E, Reeves G, et al. Childhood cancer and paternal employment in agriculture: the role of pesticides. Br J Cancer 1998;77:825-9.

13 Fear NT, Roman E, Reeves G, et al. Are the children of fathers whose jobs involve contact with many individuals at an increased risk of leukaemia? Occup Environ Med 1999:56:438-42. 
14 Fear NT, Roman E, Reeves G, et al. Father's occupation and childhood mortality: analysis of routinely collected data. Health Statistics Quarterly 1999;2:7-15

15 Fear NT, McKinney PA, Patterson CC, et al. Childhood type 1 diabetes mellitus and parental occupations involving social mixing and infectious contacts: two population-based case-control studies. Diabet Med 1999;16:1025-9.

16 Breslow NE, Day NE. Statistical methods in cancer research. Volume 1. The analysis of case-control studies. IARC Scientific Publications No. 32. Lyon: IARC, 1980.

17 UK Childhood Cancer Study Investigators. Childhood cancer and residential proximity to power lines. Br J Cancer 2000;83:1573-80.

18 UK Childhood Cancer Study Investigators. Breast feeding and childhood cancer. Br J Cancer 2001;85:1685-94.

19 Gardner MJ, Snee MP, Hall AJ, et al. Results of case-control study of leukaemia and lymphoma among young people near Sellafield nuclear plant in West Cumbria. BMJ 1990;300:423-9.

20 Draper GJ, Little MP, Sorahan T, et al. Cancer in the offspring of radiation workers: a record linkage study. BMJ 1997;315:1181-8.

21 Roman E, Doyle P, Maconochie N, et al. Cancer in children of nuclear industry employees: report on children aged under 25 years from nuclear industry family study. BMJ 1999;318:1443-50.

22 Doll R, Evans HJ, Darby SC. Paternal exposure not to blame. Nature 1994;267:678-80.

23 Little J. Epidemiology of childhood cancer. International Agency for Research on Cancer Scientific Publications No. 149. IARC: Lyon, 1999.

24 Yeni-Komshian H, Holly EA. Childhood brain tumours and exposure to animals and farm life: a review. Paediatr Perinat Epidemiol 2000;14:248-56.

25 Cordier S, Mandereau L, Preston-Martin S, et al. Parental occupations and childhood brain tumors: results of an international case-control study. Cancer Causes Control 2001;12:865-74.

26 Fabia J, Thuy TD. Occupation of father at time of birth of children dying of malignant diseases. British Journal of Preventative \& Social Medicine 1974:28:98-100.

27 Hakulinen T, Salonen T, Teppo L. Cancer in the offspring of fathers in hydrocarbon-related occupations. British Journal of Preventative \& Social Medicine 1976;30:138-40.

$28 \mathrm{Kwa}$ SL, Fine $\amalg$. The association between parental occupation and childhood malignancy. J Occup Med 1980;22:792-4.

29 Zack M, Cannon S, Loyd D, et al. Cancer in children of parents exposed to hydrocarbon-related industries and occupations. Am J Epidemiol 1980;111:329-36.

30 Hemminki K, Saloniemi I, Salonen T, et al. Childhood cancer and parental occupation in Finland. J Epidemiol Community Health 1981;35:11-15.

31 Gold EB, Diener MD, Szklo M. Parental occupations and cancer in childrena case-control study and review of the methodologic issues. J Occup Med 1982;24:578-84.

32 Shaw GM, Lavey R, Jackson R, et al. Association of childhood leukemia with maternal age, birth order, and paternal occupation. Am J Epidemiol 1984;1 19:788-95.

33 Vianna NJ, Kovasznay B, Polan A, et al. Infant leukaemia and parental exposure to motor vehicle exhaust fumes. J Occup Med 1984:26:679-82.

34 van Steensel-Moll HA, Valkenburg HA, van Zanen GE. Childhood leukemia and parental occupation. Am J Epidemiol 1985;121:216-24.

35 Lowengart RA, Peters JM, Cicioni C, et al. Childhood leukemia and parents' occupational and home exposures. J Natl Cancer Inst 1987;79:39-46.

36 McKinney PA, Cartwright RA, Saiu JM, et al. The inter-regional epidemiological study of childhood cancer (IRESCC): a case-control study of aetiological factor in leukaemia and lymphoma. Arch Dis Child 1987:62:279-87

37 Shu XO, Gao YT, Brinton LA, et al. A population-based case-control study of childhood leukemia in Shanghai. Cancer 1988:62:635-44.

38 Buckley JD, Robison LL, Swotinsky R, et al. Occupational exposures of parents of children with acute nonlymphocytic leukemia: a report from the Childrens Cancer Study Group. Cancer Res 1989:49:4030-7.
39 McKinney PA, Alexander FE, Cartwright RA, et al. Parental occupations of children with leukaemia in west Cumbria, north Humberside, and Gateshead. BMJ 1991;302:681-7.

40 Olsen JH, de Nully Brown P, Schulgen G, et al. Parental employment at time of conception and risk of cancer in offspring. Eur J Cancer 1991;27:958-65.

41 Feingold L, Savitz DA, John EM. Use of a job-exposure matrix to evaluate parental occupation and childhood cancer. Cancer Causes Control 1992:3:161-9.

42 Roman E, Watson A, Beral V, et al. Case-control study of leukaemia and nonHodgkin's lymphoma among children aged 0-4 years living in west Berkshire and north Hampshire health districts. BMJ 1993;306:615-21.

43 Shu XO, Stewart $P$, Wen WQ, et al. Parental occupational exposure to hydrocarbons and risk of acute lymphocytic leukemia in offspring. Cancer Epidemiol Biomarkers Prev 1999;8:783-91.

44 Schüz J, Kaletsch U, Meinert R, et al. Risk of childhood leukemia and parental self-reported occupational exposures to chemicals, dusts, and fumes: results from pooled analyses of German population-based case-control studies. Cancer Epidemiol Biomarkers Prevention 2000;9:835-8.

45 Feychting $M$, Plato N, Nise G, et al. Paternal occupational exposures and childhood cancer. Environmental Health Perspectives 2001;109:193-6.

46 Sanders BM, White GC, Draper GJ. Occupations of fathers of children dying from neoplasms. J Epidemiol Community Health 1981;35:245-50.

47 Smulevich VB, Solionova LG, Belyakova SV. Parental occupation and other factors and cancer risk in children: II. Occupational factors. Int J Cancer 1999;83:718-22.

48 International Agency for Research on Cancer. Benzene. Number 29. IARC monographs on the evaluation of carcinogenic risks to humans. Lyon: IARC, 1982.

49 International Agency for Research on Cancer. Diesel and gasoline engine exhausts and some nitroarenes. Number 46. IARC monographs on the evaluation of carcinogenic risks to humans. Lyon: IARC, 1989.

50 Expert Panel on Air Quality Standards. Benzene. London: Department of the Environment, Transport and the Regions, 1994.

51 Smith MT. The mechanism of benzene-induced leukaemia: a hypothesis and speculations on the causes of leukaemia. Environmental Health Perspectives 1996;104:1219-25.

52 Golding BT, Watson WP. Possible mechanisms of carcinogenesis after exposure to benzene. In: Singer B, Bartsch H, eds. Exocyclic DNA adducts in mutagenesis and carcinogenesis. International Agency for Research on Cancer Scientific Publication No. 150. Lyon: IARC, 1999.

53 Savitz DA, Feingold L. Association of childhood cancer with residential traffic density. Scand J Work Environ Health 1989;15:360-3.

54 Feychting $M$, Svensson D, Ahlbom A. Exposure to motor vehicle exhaust and childhood cancer. Scand J Work Environ Health 1998;24:8-1 1.

55 Raaschou-Nielsen O, Hertel O, Thomsen BL, et al. Air pollution from traffic at the residence of children with cancer. Am J Epidemiol 2001;153:433-43.

56 Nishi M, Miyake H. A case-control study of non-T cell acute lymphoblastic leukaemia of children in Hokkaido, Japan. J Epidemiol Community Health 1989;43:352-5.

57 Anderson LM, Diwan BA, Fear NT, et al. Critical windows of exposure for children's health: cancer in human epidemiological studies and neoplasms in experimental animal models. Environmental Health Perspectives 2000; 108:573-94

58 Savitz D, Chen J. Parental occupation and childhood cancer: review of epidemiologic studies. Environmental Health Perspectives 1990;88:325-37.

59 Sorahan T, Gilthorpe MS. Non-differential misclassification of exposure always leads to an underestimate of risk: an incorrect conclusion. Occup Environ Med 1994:51:839-40.

60 Law GR, Smith AG, Roman E. The importance of full participation: lessons from a national case-control study. Br J Cancer 2002;86:350-5.

61 Rothman KJ. No adjustments are needed for multiple comparisons. Epidemiology 1990;1:43-6. 